\title{
IN VITRO ASSEMBLY OF THE MURINE CORONAVIRUS MEMBRANE
}

\section{PROTEIN E1}

\author{
Peter Rottier, Dorothée Brandenburg, John \\ Armstrong*, Ben van der Zeijst, and Graham \\ Warren* \\ Institute of Virology, Veterinary Faculty, State \\ University, Yalelaan 1, 3508 TD Utrecht, The \\ Netherlands \\ *European Molecular Biology Laboratory, Postfach \\ 10.2209, 69 Heidelberg, FRG
}

\section{INTRODUCTION}

One of the most striking differences between coronaviruses and other enveloped RNA viruses is that they bud into intracellular membranes. Only bunyaviruses behave similarly (1).

Coronavirions have been observed in the lumens of endoplasmic reticulum (ER) and Golgi apparatus from cells infected with various coronaviruses such as mouse hepatitis virus (MHV) (2-5), avian infectious bronchitis virus (IBV) (6) and porcine enteric coronavirus (7) The assembled virions then appear in smooth-walled vesicles en route to the plasma membrane (PM) where they are probably released from the cell by exocytosis $(4,8)$.

The intracellular budding site of coronaviruses seems to be determined by one of its two envelope glycoproteins, E1, which stays in internal membranes after its synthesis on membrane-bound ribosomes $(4,5)$. The other g1ycoprotein, E2, is also assembled in the rough ER, but is not needed for virus maturation and release. Incorporation of E2 into virions is, however, essential for virus infectivity $(3,9)$. Some E2 passes to the cell surface where it fuses adjacent cells together thereby spreading the infection. E2 is similar to the spike glycoproteins of those viruses that bud at the PM in taking the same route through the ce11, passing through the Golgi complex, being fatty acylated and having normal $\mathrm{N}$-linked oligosaccharides (10). In contrast, the E1 protein has neither fatty acid groups nor N-linked oligosaccharides, instead it has 0-1inked oligosaccharides 
$(3,9,10)$ which are probably acquired in the Golgi complex $(5,11)$ as the virions pass through the stacks of Golgi cisternae.

Viral glycoproteins have widely been used as models to study the biosynthesis and fate of those cellular membrane glycoproteins that are normally transported to the PM. The unusual behaviour of the coronavirus E1 glycoprotein implicates it as an intracellular transmembrane protein which can be used as a model to study the biogenesis of (proteins of) intracellular membranes. As a first step in characterization we report the assembly of this protein in microsomal membranes in cell-free extracts. The results show several striking differences between this glycoprotein and those that are normally transported to the cell surface.

\section{MATERIALS AND METHODS}

MHV strain A59 was grown in Sac $(-)$ cells, labelled with ${ }^{35}$ Smethionine, and purified as described previously $(12,13)$. Iodination of the virus was carried out using Iodogen (14) and the final specific activity was $1.9 \mathrm{uCI} / \mathrm{ug}$. Poly $(\mathrm{A})^{+}$-RNA from infected cells was prepared as described previously (13) except that poly(U)-Sepharose (15) was used to select the RNA. The RNA was translated in nuclease-treated rabbit reticulocyte lysates essentially as described by Pelham and Jackson (16). Incubations were for $1 \mathrm{~h}$ at $30^{\circ} \mathrm{C}$. Where specified, dog pancreatic microsomes, prepared according to Blobel and Dobberstein (17) and treated with EDTA (18), were added. They were kindly provided by David Meyer (EMBL). N-formy1-35S-methiony1-tRNA f met was prepared essentially as described by Stanley (19). For immunoprecipitation, translation products were incubated overnight at $4^{\circ} \mathrm{C}$ with mouse anti-MHV-A59 serum (12), pre-immune mouse serum, or monoclonal anti-E1 (a kind gift from Marck Koolen, Institute of Virology, State University, Utrecht) and then treated for $5 \mathrm{~h}$ at $4^{\circ} \mathrm{C}$ with affinity-purified rabbit anti-mouse IgG, kindly provided by Brian Burke (EMBL). Immune-complexes were isolated essentially as described by Green et al. (20). Protease digestions were carried out by diluting the translation mixtures five-fold using $1.25 \mathrm{mg} / \mathrm{ml}$ proteinase $\mathrm{K}$ (Serva) in $50 \mathrm{mM}$ Tris-HC1 buffer $\mathrm{pH} 7.4,100 \mathrm{mM} \mathrm{NaCl}$ and incubating at $37^{\circ} \mathrm{C}$ for $15 \mathrm{~min}$ in the presence or absence of $0.05 \%$ saponin (Sigma). After cooling on ice they were treated for $10 \mathrm{~min}$ with excess phenylmethylsulfonylfluoride (PMSF) to inhibit proteinase $K$ activity. The samples were then precipitated with TCA or extracted with Triton X-114 (21). Proteins were analyzed by fractionation on $15 \%$ SDS-polyacrylamide gels with 4 or $5 \%$ stacking gel essentially as described previously (13, 20). Further details on the procedures used will be published elsewhere. 
RESULTS

E1 assembled in microsomal membranes is neither cleaved nor 1ycosylated

Sac (-) cells were infected with coronavirus A59 and, 8-9 h later, poly(A) ${ }^{+}$-RNA was extracted. When translated in a reticulocyte lysate many proteins were synthesized (cf lanes 1,2 and 3,4, Fig.1) and two (nucleocapsid (N) and E1) were tentatively identified as viral proteins, the rest presumably being derived from host cellular mRNAs. The identity of the E1 protein was

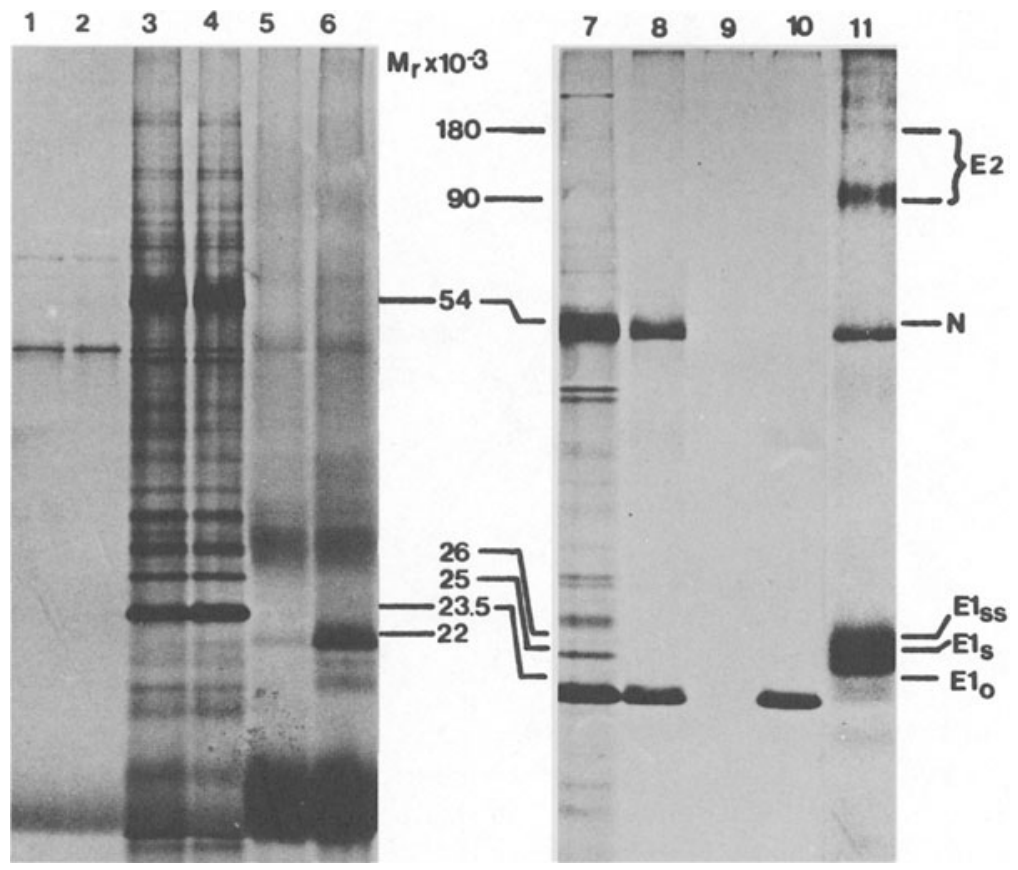

Fig.1. Synthesis of the E1 protein in the presence and absence of microsomal. membranes. Samples of incubations in the absence (lanes 1,2 ) or presence (lanes 3,4 ) of poly $(A)^{+}-$RNA and in the absence (lanes 1,3) or presence (lanes 2,4) of microsomes were taken for direct analysis by SDS-PAGE. Samples of proteins synthesized in the absence (lane 3) or presence (lane 4) of microsomes were treated with proteinase $\mathrm{K}$ and applied to lanes 5 and 6 , respectively. The identity of the capsid (N) and E1 protein was confirmed by immune precipitation from proteins synthesized in the presence of microsomes (lanes 4,7) using polyclonal anti-MHV-A59 antibodies (lane 8), pre-immune serum (lane 9) and monoclonal anti-E1 (lane 10). Lane 11 is iodinated virus. $\mathrm{E} 1_{\mathrm{o}}$ is unglycosylated $\mathrm{E} 1$, whereas $\mathrm{E} 1_{\mathrm{S}}$ and $\mathrm{E} 1_{\mathrm{ss}}$ have sugars. 


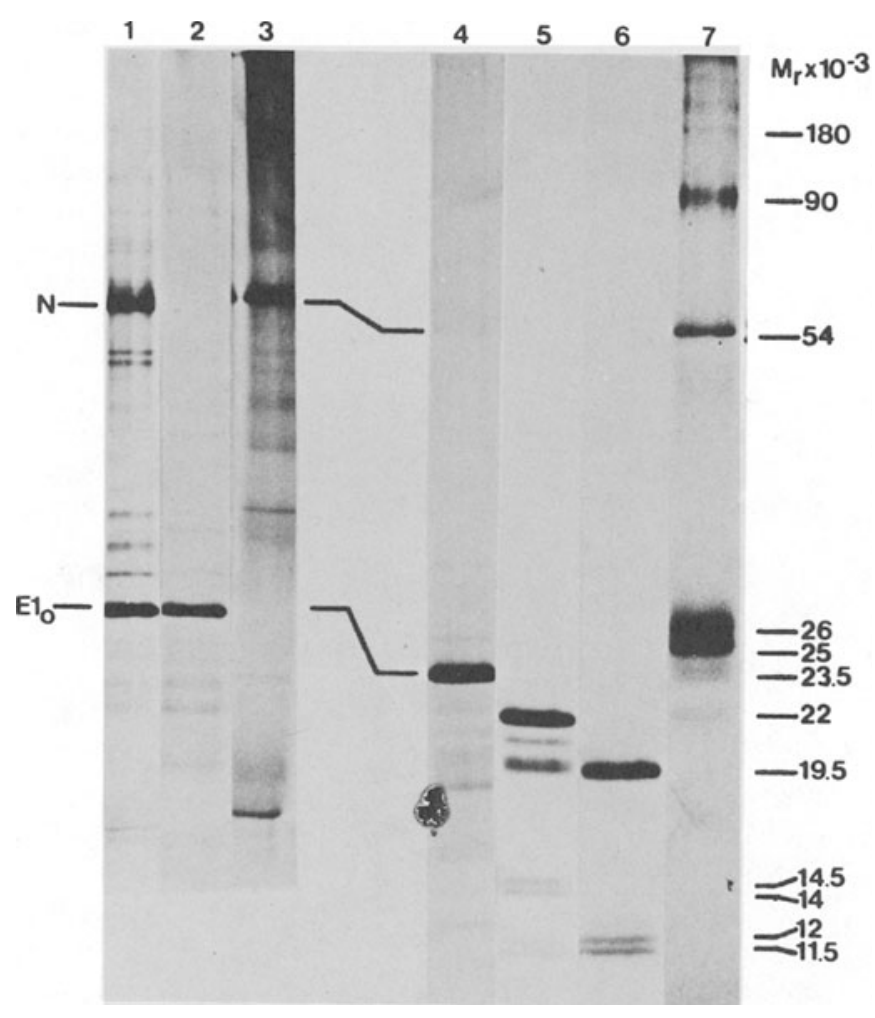

Fig.2. Protease digestion of the E1 protein synthesized in the presence of microsomes. Lanes 1-3, the El protein is purified by Triton X-114 extraction. After translation of poly $(A)^{+}-$RNA in the presence of microsomes (lane 1) a sample was extracted with Triton X-114 at $30^{\circ} \mathrm{C}$ and the detergent phase containing E1 (lane 2) was separated by centrifugation from the aqueous phase (lane 3). Lanes 4-6, protease digestion of E1 synthesized in the presence of microsomes and purified by Triton X-114 extraction. Lane 4, original incubation. Lanes 5 and 6 , samples treated with proteinase $\mathrm{K}$ alone or in the presence of $0.05 \%$ saponin, respectively. Lane 7 is iodinated virus.

confirmed using specific antibodies. A $23.5 \mathrm{kD}$ polypeptide was specifically precipitated from the total translation mixture by antiserum to the whole virus (Fig.1, lane 8) and a monoclonal anti-E1 (Fig.1, lane 10) but not by pre-immune serum (Fig.1, lane 9). 


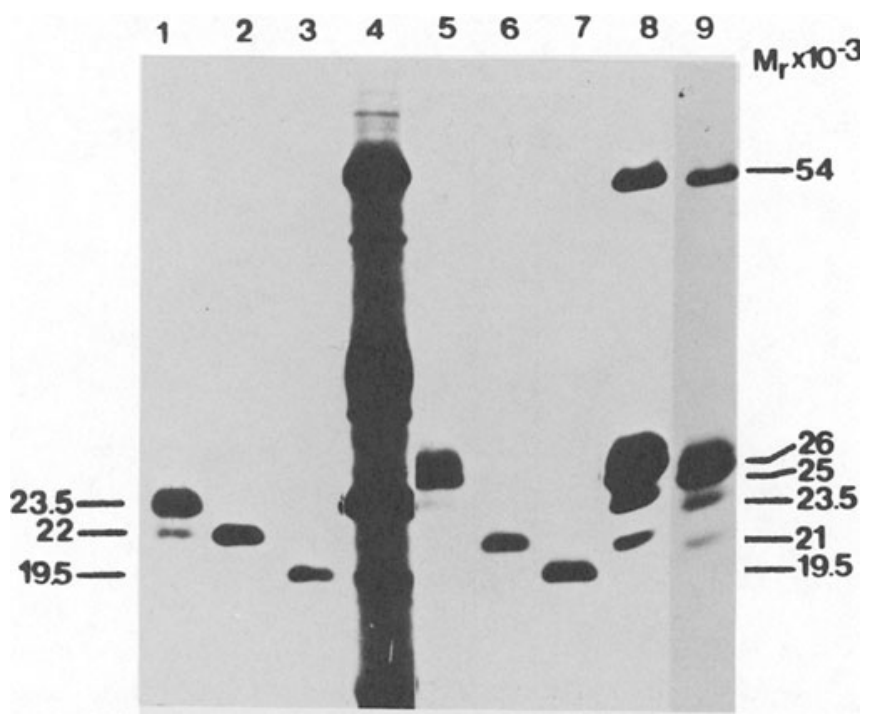

Fig 3. Protease digestion of labelled virions and of E1 synthesized in the presence of microsomes. Lanes 1-4 are directly comparable to lanes $4-6$ and 1 , respectively, of Fig.2. Lanes 5-8, protease digestion of 35 S-methioninelabelled virus. The virus (lane 8) was treated with proteinase $\mathrm{K}$ in the presence (lane 5) or absence (lane 6) of PMSF, or in the presence of $0.05 \%$ saponin (lane 7 ). Lane 9 is a shorter exposure of lane 8 .

E1 synthesized in the absence of dog pancreatic microsomes (Fig.1, lane 3) could be digested completely by protease (Fig.1, lane 5). Synthesis in the presence of microsomes (Fig.1, lane 4) yielded an El protein of the same molecular weight but most of this was resistant to protease digestion (Fig.1, lane 6) indicating that assembly into the membrane had occurred. The absence of any change in molecular weight after assembly into microsomes strongly suggests that the signal sequence is uncleaved, a suggestion strongly confirmed by N-terminal labelling of the protein (see below). The assembled E1 protein also co-migrated with unglycosylated El in virions (Fig.1, cf. lanes 10 and 11) suggesting that addition of 0-1inked oligosaccharides occurs after the completed protein has been transported from the rough ER.

E1 spans the lipid bilayer

E1 was separated from the background of non-viral proteins by exploiting the phase separation properties of Triton X-114 (21). Since El behaves as an integral membrane protein (22) it was selectively extracted into the detergent phase of a Triton X-114 


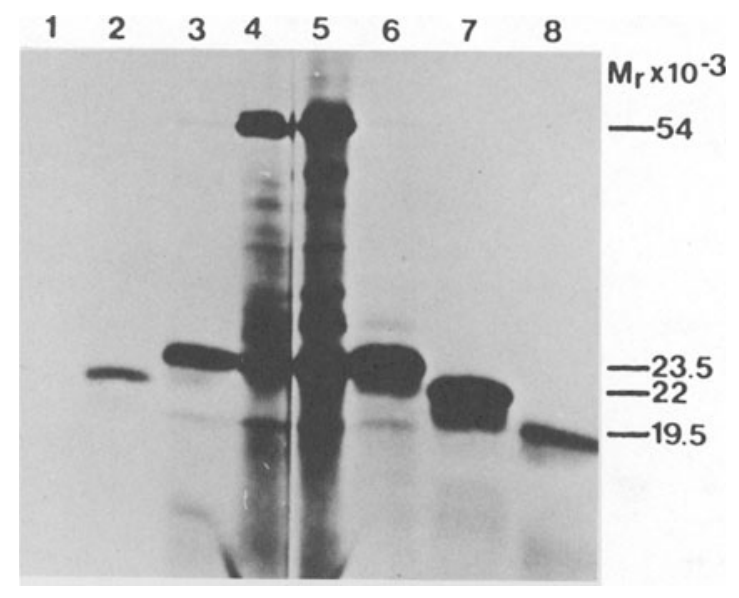

Fig.4. N-terminal labelling of E1. Poly(A) -RNA was translated in the presence of microsomes in a mixture containing $0.1 \mathrm{mM}$ methionine and $\mathrm{N}$-formyl-35S-methionyl-tRNA $\mathrm{f}_{\mathrm{met}} \mathrm{t}$ A sample of the original incubation (lane 4) was extracted with Triton $\mathrm{X}-114$ to purify E1 (lane 3 ). Two samples were treated with proteinase $K$ either in the absence (lane 2) or in the presence (lane 1) of $0.05 \%$ saponin. For comparison a normal translation using $35 \mathrm{~S}$-methionine was performed and analyzed in parallel. Lane 5, direct analysis; lanes 6-8, Triton X114 extracts before (lane 6) or after treatment with proteinase $\mathrm{K}$ in the absence (lane 7 ) or presence of $0.05 \%$ saponin (lane 8 ).

suspension at $30^{\circ} \mathrm{C}$ (Fig.2, lane 2) leaving soluble proteins such as the nucleocapsid $(\mathrm{N})$ and host cell proteins in the aqueous phase (Fig.2, lane 3).

After protease treatment of translation mixtures containing microsomal membranes the $23.5 \mathrm{kD}$ form of $\mathrm{E} 1$ was no longer visible and the major product had a Mr of $22 \mathrm{kD}$ (Fig.2, cf. lanes 4 and 5 , Fig.3, cf. lanes 1 and 2). A $1.5 \mathrm{kD}$ fragment had thus been removed from the equivalent of the cytoplasmic side of the ER membrane in vivo. Previous studies have shown that $E 1$ is accessible to protease in intact virions (22). The different forms of E1, which are presumably 0-glycosylated to different extents (9) on that part of the protein exposed on the virion surface, are all digested to a common fragment of $21 \mathrm{kD}$ (Fig.3, cf. lanes 5 and 6). Since the virus buds into the ER lumen, the virion outer surface is topologically equivalent to the lumenal side of the ER. E1 is thus accessible to protease from the cytoplasmic and lumenal sides of the ER membrane and must therefore span the bilayer. 
This was demonstrated directly by permeabilizing the microsomal vesicles with the detergent saponin. When microsomal vesicles were treated with protease in the presence of $0.05 \%$ saponin the $E 1$ protein was quantitatively converted into a fragment with a Mr of $19.5 \mathrm{kD}$ (Fig.2, cf. lanes 4 and 6, Fig.3, cf. lanes 1 and 3 ). Treatment of intact virions under the same conditions gave a fragment of exactly the same size (Fig.3, cf., lanes 5 and 7), the size of which was that expected if El had been digested from both sides of the membrane. It would thus seem that saponin makes the membrane permeable to added protease but does not otherwise affect the protein. Complete disruption of the bilayer using Triton $\mathrm{X}-100$ made the E1 protein completely sensitive to protease digestion (data not shown). An E1 fragment of the same mobility ( $\mathrm{Mr} .19 .5 \mathrm{kD}$ ) was observed in some experiments in the absence of saponin (Fig.2, lane 5, Fig.4, lane 7). Since microsomal vesicles are known to be leaky to proteases to some extent (23) the fragment is probably derived by digestion of E1 from both sides of the bilayer. For analytical purposes, saponin treatment is advantageous in ensuring that all the microsomal vesicles are permeable to the protease.

The E1 fragment that is resistant to protease digestion from both sides of the membrane is large enough to contain up to seven polypeptide segments spanning the bilayer, although its precise topology in the membrane remains to be elucidated. The presence of minor proteolytic fragments of El does, however, suggest that one loop of this fragment is accessible to protease to a limited extent on the outside of microsomal vesicles. Depending on which part of the loop is cleaved the minor fragment has a Mr of $14 \mathrm{kD}$ or $14.5 \mathrm{kD}$ (Fig.2, lane 5). In the presence of saponin this drops to 11.5 and $12 \mathrm{kD}$ (Fig.2, lane 6). The proposed topology that would result in these fragments is presented in Fig. 6 and will be discussed below.

The $\frac{\text { N-terminus }}{\text { Since E1 }} \frac{\mathrm{E} 1}{\text { is }} \frac{\text { is }}{\text { not }} \frac{\text { on }}{\text { prote the }} \frac{\text { lumenal }}{\text { ically }}$ side $\frac{\text { of }}{\text { cleave }} \frac{\text { the }}{\text { during }} \frac{\text { membrane }}{\text { assembly }}$ in microsomal vesicles it proved possible to label the N-terminus selectively using N-formy1- ${ }^{35}$ S -methionyl-tRNA met. This label was present on the assembled E1 protein (Fig.4, ${ }^{\mathrm{f}}$ lane 3 ) and on the $22 \mathrm{kD}$ fragment generated by protease digestion (Fig.4, lane 2) showing that the N-terminus was not on the cytoplasmic side of the membrane. Digestion in the presence of saponin resulted in complete loss of the label (Fig.4, lane 1), indicating that the $\mathrm{N}$ terminus is on the lumenal side of the ER membrane. The presence of each of the proteolytically-derived forms of E1 was confirmed in parallel experiments using ${ }^{35} \mathrm{~S}$-methionine as the radiolabel (Fig.4, lanes 5-8). 


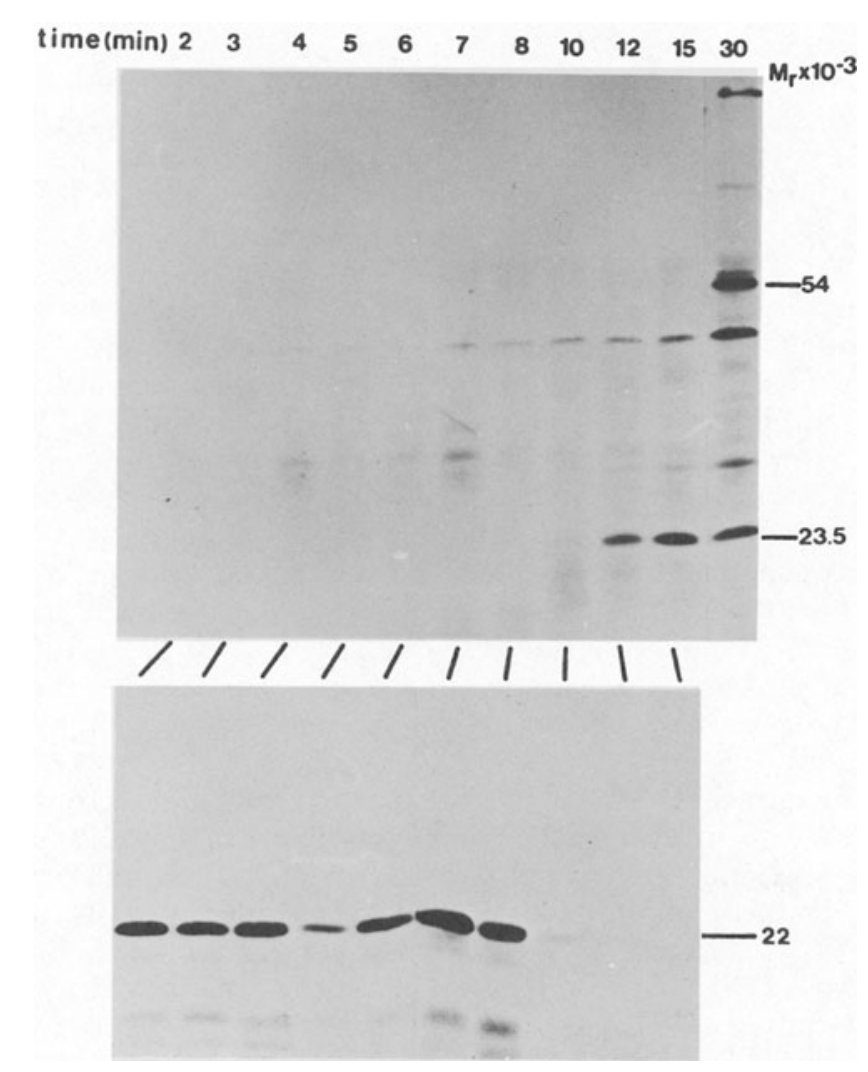

Fig.5. Addition of microsomes at different times after initiation of protein synthesis. Poly(A)+-RNA was added at zero time to initiate synthesis at $250^{\circ}$. Two minutes later edeine (final concentration $1.2 \mathrm{uM}$ ) was added and incubation continued at $30{ }^{\circ} \mathrm{C}$. At the times shown above the lanes samples were removed either for direct analysis (top panel) or for further incubation in the presence of microsomes until $t=30$ min. These samples were then treated with proteinase $\mathrm{K}$, extracted with Triton $\mathrm{X}-114$ and fractionated by SDS-PAGE (bottom pane1).

E1 can enter the membrane at late stages of synthesis

Protein synthesis was started in the cell-free system by the addition of poly(A) ${ }^{+}$-RNA. After two minutes, edeine was added to prevent further initiation (24). At different times samples were taken for direct analysis by SDS-PAGE or added to microsomal membranes and incubated at $30^{\circ} \mathrm{C}$ until 30 min after the additon of poly $(A)^{+}$-RNA to allow assembly to occur. These samples were then first protease-treated, to distinguish between soluble E1 and that assembled in microsomal membranes, and then extracted with Triton 
X-114 and fractionated by SDS-PAGE. As shown in Fig.5 (top), ful1length E1 appeared after about $12 \mathrm{~min}$ synthesis at $30{ }^{\circ} \mathrm{C}$ corresponding to a synthetic rate of about 8 amino acids polymerized/min, a rate that was not affected when synthesis was carried out in the presence of microsomal membranes (data not shown). It proved possible to add microsomal membranes as late as 8 min after the start of synthesis and assemb1y would still occur (Fig.5, bottom). This corresponds to the synthesis of $65-70 \%$ of the E1 protein, or 140-150 amino acids.

\section{DISCUSSION}

Our study of the in vitro assembly of MHV-A59 envelope protein $E 1$ into membranes reveals new and unusual features of this protein in addition to those previously known. One striking observation was that this protein, once assembled into microsomal membranes, appears to be largely buried in the lipid bilayer: more than $80 \%$ of it has become resistant to proteolysis. Apparently only short regions of 2.5 and $1.5 \mathrm{kD}$, from the $\mathrm{N}-$ and C-termini, are exposed to the lumenal and cytoplasmic compartments,

A
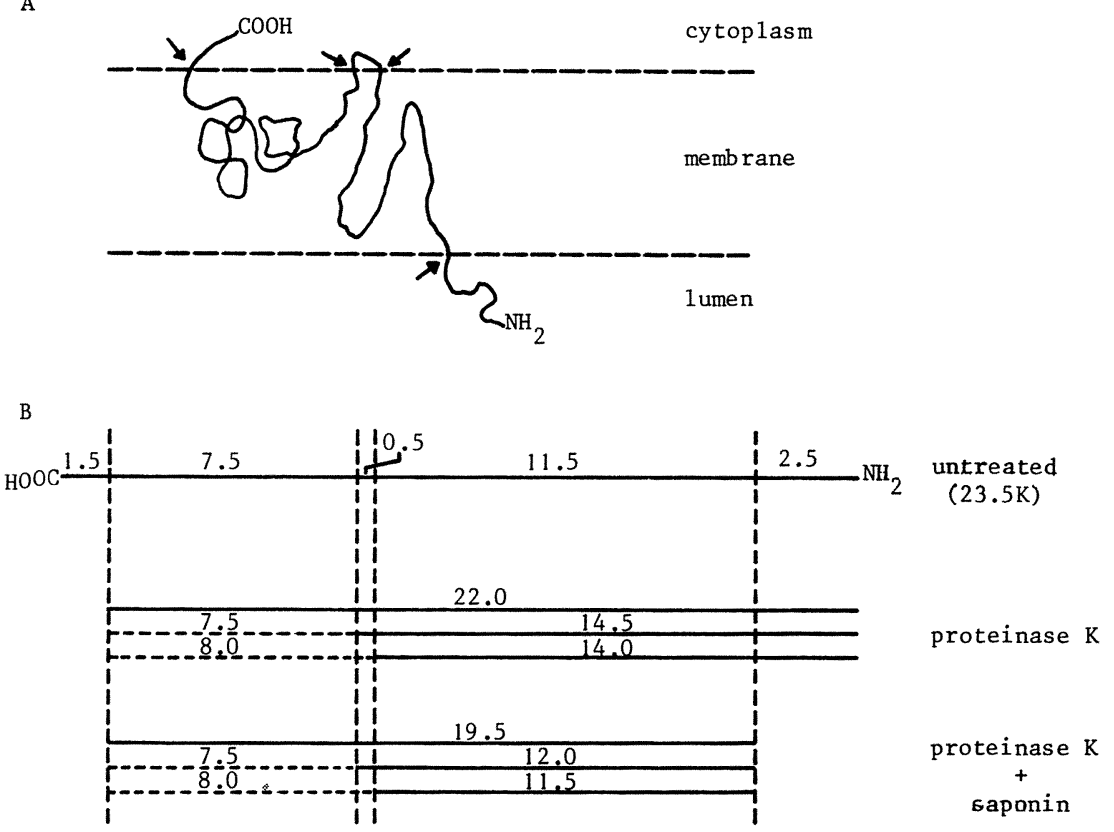

Fig.6. Schematic view of the topology of the $E 1$ protein in the microsomal membrane. (A) summarizes the data presented in this paper. (B) represents the postulated cleavages observed using proteinase $\mathrm{K}$ as indicated by arrows in (A). 
respectively. The remainder is sufficiently large to span the membrane several times, as shown schematically in Fig.6. This would be a novel feature for a viral glycoprotein, although several non-viral proteins are known which apparently cross the membrane more than once (25-28). Only bacteriorhodopsin is comparable, however, in appearing to lack substantial domains on either side of the membrane (29), but this protein is found in the unusual membrane of an Archaebacterium.

Insertion of $\mathrm{El}$ into membranes does not lead to the cleavage of an N-terminal leader peptide (Figs.1 and 4) as does usually occur with membrane glycoproteins. Other examples of spanning membrane proteins without a cleavable signal sequence are rhodopsin (30) and Band III protein (31); the same phenomenon has been found for a secreted protein, ovalbumin (32). No N-terminal peptide being cleaved off, the signal for insertion of E1 into membranes might well be located elsewhere in the molecule. Studying therefore the kinetics of its insertion, we found that the molecule can penetrate the membrane even after a large proportion of it, approximately 140-150 amino acids, has been synthesized (Fig.5). Thus the insertion signal could in principle be located anywhere within this region. A further comparison with ovalbumin and Band III protein can be made. It has been proposed that the signal sequence for these proteins is internal rather than N-terminal $(31,33)$, although the precise location for ovalbumin remains controversial (34).

The E1 protein does not acquire its 0-1inked oligosaccharides in the rough ER, a result which confirms the cell fractionation data obtained by Niemann et al. (5). It is likely that these oligosaccharides are acquired as the completed virions pass through the Golgi complex $(5,11)$. The attachment of the sugars to the $2.5 \mathrm{kD} N$-terminal domain seemed not to have altered the proteins' intramembranous configuration. In this respect a comparison between the E1 protein of murine and avian viruses will be valuable, since infectious bronchitis virus E1 is glycosylated only through $\mathrm{N}$-1inked oligosaccharides (35). 0-linked sugars on animal virus structural proteins are rather rare. Their functions are still speculative. Glycoproteins bearing 0-1inked sugars have been described for vaccinia (36) and herpesvirus (11). It is interesting to note that these viruses also mature by budding from intracellular membranes.

The budding of MHV-A59 virions presumab1y involves the specific interaction between nucleocapsids present in the cytoplasm and El in ER membranes. Our results suggest that only the $1.5 \mathrm{kD}$ C-terminal fragment of El is effectively available for such an interaction. It is probably this tiny portion of the molecule which is responsible for the high affinity of E1 for RNA (37). 
Thus, the El glycoprotein of coronavirus has several features which distinguish it from the majority of membrane proteins. Some of these features should be clarified by analysis of the amino acid sequence of the protein (Armstrong et al., this volume).

ACKNOWLEDGEMENTS

We thank Bernard Dobberstein, Sharon Queally and Paul Quinn for critical reading of the manuscript; Maud Maas Geesteranus for typing; J.A. was supported by a European Fellowship from the Royal Society, and P.R. was supported at the EMBL by a short-term fellowship from the European Molecular Biology Organization.

\section{REFERENCES}

1. J.F. Smith and D.Y. Pifat, Virology 121:61 (1982).

2. A. Massalski, M.Coulter-Mackie and S.Dales, in: "Biochemistry and Biology of Coronaviruses", V. ter Meulen, S. Siddell and H. Wege, eds., Plenum Press, New York and London, pp. 111-118 (1981).

3. K.V.Holmes, E.W. Doller and L.S.Sturman, Virology 115:334 (1981).

4. M.E. Dubois-Dalcq, E.W. Doller, M.V. Haspel and K.V. Holmes, Virology 119:317 (1982).

5. H.Niemann, B. Boschek, D. Evans, M. Rosing, T. Tamura and H.-D. Klenk, EMBO J. 1:1499 (1982).

6. D.Chasey and D.J.Alexander, Arch.Viro1. 52:101 (1976).

7. R.Ducatelle, W.Coussement, M.B. Pensaert, P. DeBouck and J.Hoorens, Arch.Viro1. 68:35 (1981).

8. K.V.Holmes and J.N.Behnke, in: "Biochemistry and Biology of Coronaviruses", V. ter Meulen, S. Siddell and H. Wege, eds., Plenum Press, New York and London, pp. 287-299 (1981).

9. P.J.M.Rottier, M.C.Horzinek and B.A.M.van der Zeijst, J.Virol. 40:350 (1981).

10.H.Niemann, and H.-D. Klenk, J.Mol.Biol. 153:993 (1981).

11.D.C. Johnson and P.G. Spear, Cel1 32:987 (1983).

12.W.J.M.Spaan, P.J.M.Rottier, M.C. Horzinek and B.A.M.van der Zeijst, Virology 108:424 (1981).

13.P.J.M.Rottier, W.J.M.Spaan, M.C.Horzinek and B.A.M.van der Zeijst, J.Virol. 38:20 (1981).

14.B.A.M. van der Zeijst, B.E. Noyes, M.-E. Mirault, B. Parker, A.D.M.E. Osterhaus, F.A. Swyryd, N. Bleumink, M.C. Horzinek and G.R. Stark, J.Virol., in press (1983).

15.F.H.Wilt, Ce11 11:673 (1977).

16.H.R.B. Pelham and R.J.Jackson, Eur.J.Biochem. 67:247 (1976).

17.G. Blobel and B. Bobberstein, J.Ce11 Biol. 67:852 (1975).

18.H. Garoff, K. Simons and B.Bobberstein, J.Mol.Biol. 124:587 (1978). 
19.W.M. Stanley, Anal.Biochem. 48:202 (1972).

20.J. Green, G. Griffiths, D. Louvard, P. Quinn and G. Warren, J.Mo1.Biol. 152:663 (1981).

21.C. Bordier, J.Biol.Chem. 256:1604 (1981).

22.L.S. Sturman, Virology 77:637 (1977).

23.D.D. Sabatini and G. Blobel, J.Cel1 Biol. 45:146 (1970).

24.T.Obrig, J. Irvin, W. Culp and B. Hardesty, Eur.J.Biochem. $21: 31$ (1971).

25.R.Henderson and P.N.T.Unwin, Nature 257:28 (1975).

26.F.A.Dratz and P.A.Hargrave, Trends in Biochem.Sci. 8:128 (1983). 27.T.L. Steck, J.Supramol.Struc. 8:311 (1978).

28.M. Noda, H. Takahashi, T. Tanabe, M. Toyosato, S. Kikyotani, Y. Furutani, T. Hirose, H. Takashima, S. Inayama, T. Miyata and S. Numa, Nature 302:528 (1983).

29.Yu.A. Ovchinnikov, N.G. Abdulaev, M.Yu. Feigina, A.V. Kiselev, N.A. Lobanov, FEBS Lett. 100: 219 (1979).

30.I. Schechter, Y. Burstein, R. Zeme11, E. Ziv, F. Kantor and D.S. Papermaster, Proc.Nat1.Acad.Sci. USA 76:2654 (1979).

31.W.A. Braell and H.F. Lodish, Cel1 28:23 (1982).

32.R.D. Palmiter, J.Gagnon and K.A. Walsh, Proc.Nat1.Acad.Sci. USA 75:94 (1978).

33.V.R. Lingappa, J.R. Lingappa and G. Blobel, Nature 281:117 (1979).

34.R.D. Meek, K.A. Walsh and R.D. Palmiter, J.Biol.Chem. 257:12245 (1982).

35.D.F. Stern and B.M. Sefton, J.Viro1. 44:804 (1982).

36.H. Shida and S. Dales, Virology 111:56 (1981).

37.L.S. Sturman, K.V. Holmes and J. Behnke, J.Virol. 33:449 (1980). 